\title{
Synthesis And Characterization of $\mathrm{CdS} / \mathrm{CeO}_{2}$ Nanocomposite With Improved Visible-Light Photocatalytic Degradation of Methyl Orange Dye
}

Tigabu Mekonnen Bekele ( $\sim$ tgbekele19@gmail.com )

Mekdela Amba University

\section{Nano Express}

Keywords: Nanotechnology, Degradation, Photocatalyst, AOPs, Nanoparticle, Ceria

Posted Date: July 23rd, 2021

DOl: https://doi.org/10.21203/rs.3.rs-680076/v1

License: (c) (i) This work is licensed under a Creative Commons Attribution 4.0 International License. Read Full License 


\section{Abstract}

In this work, different types of photocatalysts in single ( $\mathrm{CdS}$ and $\left.\mathrm{CeO})_{2}\right)$ and binary $\left(\mathrm{CdS} / \mathrm{CeO}_{2}\right.$ in different molar ratio: 0.5:1, 1:1 and 1:0.5) systems were synthesized by co-precipitation method. Crystal structure, surface area, morphology, band gap energy, functional groups and optical properties of the assynthesized photocatalysts were characterized by using XRD, BET, SEM-EDX, UV/Vis, FTIR and PL instruments, respectively. Photocatalytic activities of single and binary nanocomposite were evaluated by using aqueous solution of model pollutant methyl orange dye (MeO). Photocatalytic activities of binary $\mathrm{CdS} / \mathrm{CeO}_{2}$ (1:1) nanocomposite were found to be higher than those of single counterparts. The photodegradation efficiencies of the binary system were found to be $53.73 \%$. The reusability of binary photocatalyst was tested and only about 33\% decrement was observed after four successive runs. Photocatalytic degradation of $\mathrm{MeO}$ dye follows the pseudo first order kinetics for the entire assynthesized nanocomposite. The results also suggest that in the $\mathrm{CdS} / \mathrm{CeO}_{2}(1: 1)$ nanocomposite the photoinduced electrons and holes can be effectively separated.

\section{Introduction}

Nature is contaminated by especially wastewater effluents of industrial manufacturing companies contain toxic organic compounds [1]. Dyes are a well-known source of environmental pollution and therefore their removal from waste water receives increasing attention. They are generally resistant to light, water, oxidizing agents and many chemicals and therefore difficult to degrade once released into the aquatic systems. Azo dyes are the largest and most versatile class of organic dye-stuffs. These contain one or more azo bonds $\left(-\mathrm{N}=\mathrm{N}^{-}\right)$as a chromophore group in association with aromatic structures containing functional groups such as $-\mathrm{OH}$ and $-\mathrm{SO}_{3} \mathrm{H}$. The complex aromatic structures of azo dyes make them more stable and more difficult to remove from the effluents discharged into the water bodies [2]. A number of physical, chemical and biological techniques had been reported for the treatment of all types of dyes with limited success.

Recently, many processes have been extensively applied for the treatment of dye containing wastewater such as: incineration, biological treatment, ozonation and adsorption on solid phase. However, these procedures have their own limitations. These is why the most advanced technique which is called advanced oxidation processes (AOPs) have been developed during the last decade since they are able to deal with the problem of dye destruction in aqueous systems.

AOPs were based on the generation of very reactive species such as hydroxyl radicals ( $\mathrm{OH}$ ) that oxidize a broad range of pollutants quickly and non-selectively [3]. AOPs such as plasma oxidation, ozonation, Fenton, photo-Fenton catalytic reactions $\mathrm{H}_{2} \mathrm{O}_{2} / \mathrm{UV}$ processes and semiconductor mediated photocatalysis have been studied under a broad range of experimental conditions in order to reduce the color and organic load of dye containing effluent waste waters $[4,5]$. 
The most important among those advanced oxidation processes is called heterogeneous photocatalytic oxidation which is often referred to as photocatalysis. This method deals with the oxidation mostly of organic molecules and compounds by means of solid metal oxide semiconductor as catalyst, which is activated by the incidence of radiation of an appropriate wavelength. It can take place both in the aqueous phase as well as in the gas phase. Among AOPs, heterogeneous photocatalysis appears as the most emerging destructive technology. Chemical treatment of wastewaters by AOPs can result in the complete mineralization of the pollutants to simple harmless end products such as carbon dioxide, water and inorganic salts. Ideally, a semiconductor photocatalyst for the purification of water should be chemically and biologically inert, photocatalitcally active, easy to produce and use, and activated by UV or sunlight [6].

Semiconductor-based photocatalysis is a promising avenue to solve the worldwide energy shortage and environmental pollution using the abundant solar light [7]. Of the well-known photocatalysts, cerium dioxide $\left(\mathrm{CeO}_{2}\right)$, as a fascinating rare earth material, has attracted much attention owing to its high activity, low cost and environmentally friendly properties [8]. It shows promising photoactivity for the degradation of organic pollutants and water splitting for hydrogen generation. Nevertheless, pristine $\mathrm{CeO}_{2}$ can only be excited by ultraviolet light (UV) because of its wide band gap (about $3.2 \mathrm{eV}$ ), limiting its further application in the visible light region. In order to highly utilize solar energy, various methods, such as doping, noble metal deposition and forming composites have been designed to enhance the absorption of $\mathrm{CeO}_{2}$ photocatalysts in the visible light region. Among them, the most effective strategy is the coupling of two semiconductors, $\mathrm{CeO}_{2}$ and another semiconductor, to form a composite [9].

There are many reports available on mixed metal oxides of $\mathrm{CeO}_{2}$ to improve its thermal stability and increase its photocatalytic performance [10]. Nanocomposites such as $\mathrm{TiO}_{2}-\mathrm{CeO}_{2}$ [11], $\mathrm{CeO}_{2}-\mathrm{ZnO}$ [12], $\mathrm{ZrO}_{2}-\mathrm{CeO}_{2}$ [13] and $\mathrm{Ag}_{3} \mathrm{PO}_{4} / \mathrm{CeO}_{2}[14]$ have been prepared and their photocatalytic activities under visible irradiation investigated.

However, the prepared binary photocatalysts have moderate photocatalytic activity under visible-light illumination. In this research, we hypothesized a good photocatalytic activity as the result of binary $\mathrm{CdS} / \mathrm{CeO}_{2} \mathrm{n}$-n heterostructured nanocomposite. $\mathrm{CdS}$ could be able to form "A-type" heterojunction with $\mathrm{CeO}_{2}$ given the more negative potential expected to be effective in exploiting both $\mathrm{e}^{-}$and $\mathrm{h}^{+}$in the redox process [15]. In this work, the principal objective is to synthesize binary $\mathrm{CdS} / \mathrm{CeO}_{2}$ and evaluates the photocatalytic activity of the as-synthesized nanocomposite for the degradation of model pollutant dye, Methyl orange $(\mathrm{MeO})$.

\section{Experimental}

\subsection{Chemicals}


Cerium nitrate hexahydrate $\mathrm{Ce}\left(\mathrm{NO}_{3}\right)_{3} \cdot 6 \mathrm{H}_{2} \mathrm{O}$ and ammonia solution (25\% Loba chemicals Ltd, India), cadmium acetate tetrahydrate $\left(\mathrm{Cd}\left(\mathrm{CH}_{3} \mathrm{COO}\right)_{2} \cdot 4 \mathrm{H}_{2} \mathrm{O}\right)$ and di-sodium sulfide $\left(\mathrm{Na}_{2} \mathrm{~S} .9 \mathrm{H}_{2} \mathrm{O}\right)$ were used as the precursors of $\mathrm{CeO}_{2}$ and $\mathrm{CdS}$, respectively. All chemicals were analytical grade and are bought from Sigma Aldrich.

\subsection{Synthesis of Photocatalysts \\ 2.2.1. Synthesis of $\mathrm{CeO}_{2}$ Nanoparticle}

Cerium oxide nanoparticle was prepared by precipitation method [16]. An aqueous solution of $0.1 \mathrm{M}$ of cerium nitrate hexahydrate $\mathrm{Ce}\left(\mathrm{NO}_{3}\right)_{3} \cdot 6 \mathrm{H}_{2} \mathrm{O}$ in deionized water was prepared and stirred for $30 \mathrm{~min}$. The clear solution was precipitated by dropwise addition of aqueous $\mathrm{NH}_{4} \mathrm{OH}$ solution with continuous stirring until precipitation gets completed. The stirring was continued for another $2 \mathrm{~h}$ and the reaction condition then maintained at $\mathrm{pH}=8$. The reaction mixture was then stirred for $12 \mathrm{~h}$ to complete the precipitation process. Ash color solution changed into yellow solution after an hour of stirring time. The mixture was aged for $12 \mathrm{~h}$. The resulting yellow colored slurry was decanted, filtered and washed several times with deionized water and ethanol. The precipitate was oven dried at $140{ }^{\circ} \mathrm{C}$ for $12 \mathrm{~h}$ and calcined at $500{ }^{\circ} \mathrm{C}$ for $3 \mathrm{~h}$ to promote the crystallization [17].

\subsubsection{Synthesis of CdS Nanoparticle}

In this study, we have used cadmium acetate tetrahydrate $\left(\mathrm{Cd}\left(\mathrm{CH}_{3} \mathrm{COO}\right)_{2} \cdot 4 \mathrm{H}_{2} \mathrm{O}\right)$ as a $\mathrm{Cd}^{+2}$ ion source and di-sodium sulfide nanohydrate $\left(\mathrm{Na}_{2} \mathrm{~S} .9 \mathrm{H}_{2} \mathrm{O}\right)$ as $\mathrm{S}^{-2}$ ion source, respectively. For the synthesis of $\mathrm{CdS}$ nanoparticle using precipitation method, equal molarity of $(0.1 \mathrm{M}) \mathrm{Cd}\left(\mathrm{CH}_{3} \mathrm{COO}\right)_{2} \cdot 4 \mathrm{H}_{2} \mathrm{O}$ and $\mathrm{Na}_{2} \mathrm{~S}_{9} \cdot \mathrm{H}_{2} \mathrm{O}$ solution were prepared in separate beakers. Then sodium sulfide solution was added dropwisely through continuous stirring for $2 \mathrm{~h}$ at room temperature to form a clear solution. During the reaction $\mathrm{N}_{2}$ gas was continuously purged through the suspension. Then the yellow precipitate was collected by centrifugation and washed three times with deionized water and ethanol to remove the residue. Finally, the obtained CdS nanoparticle was further dried at $70^{\circ} \mathrm{C}$ for $5 \mathrm{~h}$. The clean solid precipitate was calcined at $300{ }^{\circ} \mathrm{C}$ for $2 \mathrm{~h}$ in a furnace, ground into powder and kept in a container [18].

\subsubsection{Synthesis of $\mathrm{CdS} / \mathrm{CeO}_{2}$ Nanocomposite}

In a typical procedure, $0.1 \mathrm{M}$ of the as-synthesized $\mathrm{CeO}_{2}$ powder were dispersed in $100 \mathrm{~mL}$ of distilled water and sonicated for $30 \mathrm{~min}$, then $0.1 \mathrm{M}$ of $\mathrm{Cd}\left(\mathrm{CH}_{3} \mathrm{COO}\right)_{2} \cdot 4 \mathrm{H}_{2} \mathrm{O}$ was added. After $1 \mathrm{~h}$ of stirring, equal molarity of $\mathrm{Na}_{2} \mathrm{~S} .9 \mathrm{H}_{2} \mathrm{O}$ solution was added dropwisely into the mixed solution. The precipitate was filtered and washed with distilled water and ethanol several times, and then dried in an oven at $60^{\circ} \mathrm{C}$ for $24 \mathrm{~h}$ to obtain $\mathrm{CdS} / \mathrm{CeO}_{2}$ nanocomposite [19]. The $\mathrm{CdS} / \mathrm{CeO}_{2}$ nanocomposite was done in four molar ratios $(0.5: 1,1: 1$ and $1: 0.5)$ of $\mathrm{CdS}: \mathrm{CeO}_{2}$. The obtained powder was then ground to get fine particles.

\subsection{Characterization of the As-synthesized Photocatalysts}




\subsubsection{X-ray Diffraction (XRD) Study}

The structures of all the as-synthesized photocatalyst were examined by XRD at room temperature at step scan rate of $0.02^{\circ}$ (step time: $1 \mathrm{~s} ; 2 \theta$ range: $5.0-90.4^{\circ}$ ), which is equipped with an X-ray source of a CuKa radiation (wavelength of $0.15406 \mathrm{~nm}$ ) using $45 \mathrm{kV}$ accelerating voltage and $40 \mathrm{~mA}$ applied current. Finally, XRD patterns were collected with X'Pert Pro PANalytical.

\subsubsection{Determination of Surface Area}

The specific surface area of each of the as-synthesized photocatalyst were calculated from the $\mathrm{N}_{2}$ adsorption-desorption isotherm at liquid-nitrogen temperature $-196{ }^{\circ} \mathrm{C}(77 \mathrm{~K})$ and the micropore surface area were calculated by using the Brunauer-Emmett-Teller (BET) method.

\subsubsection{SEM-EDX Study}

Solid morphologies and particle distribution of the as-synthesized photocatalyst were determined by scanning electron micrographs (SEM Hitachi TM1000 with EDX detector) with a backscattered detector instrument; a gold film was sputtered into the sample prior to observation. From energy dispersive X-ray [EDX, an acquisition time (s) 40.0; process time $3 \mathrm{~h}$; and an accelerating voltage (kV) 15.0)] link with SEM the elemental percent weight distribution of the as-synthesized sample was determined.

\subsubsection{UV/Vis Diffuse Reflectance Study}

The optical absorption spectra and band gaps of the as-synthesized photocatalysts were determined using UV/Vis spectrophotometer. The solid state absorbance of the photocatalyst was measured by scanning over the wavelength range of $200-900 \mathrm{~nm}$.

\subsubsection{FTIR Study}

The as-synthesized photocatalyst was characterized using FTIR (Spectrum 65, PerkinElmer) instrument. Dry mass of the photocatalyst was thoroughly mixed with a given dry mass of $\mathrm{KBr}$ and ground to a fine powder. A transparent disc was formed by applying a pressure in moisture free atmosphere. The IR absorption spectrum was recorded between 400 and $4000 \mathrm{~cm}^{-1}$.

\subsubsection{Photoluminescence (PL) Study}

Photoluminescence (PL) spectra were measured at Haramaya University using RF 5301PC Shimadzu photoluminescence. The spectra were obtained in the range of $250-650 \mathrm{~nm}$.

\subsection{Photocatalytic Degradation Studies}

Photocatalytic activities of the entire as-synthesized sample were tested for the degradation of aqueous solution of methyl orange $(\mathrm{MeO})$ dye. For example in typical photocatalytic experiment, $10 \mathrm{ppm}$ of $\mathrm{MeO}$ was mixed with $0.2 \mathrm{~g} / \mathrm{L}$ of the photocatalyst. The mixture was magnetically stirred for $1 \mathrm{~h}$ in the dark to ensure adsorption/desorption equilibrium. Then the suspension was irradiated with visible light irradiation with continuous stirring using magnetic stirrer and the absorbance was measured in 20 min 
time interval to monitor the reaction of $\mathrm{MeO}$ aqueous solution degradation. The distance between the light source and the dye solution is $20 \mathrm{~cm}$. During the process air/oxygen was purged in to the solution using pipette. Then $10 \mathrm{~mL}$ suspension was withdrawn at $20 \mathrm{~min}$ time interval and centrifuged at 3000 rpm for $10 \mathrm{~min}$. Dye absorbance was determined using UV/Visible spectrophotometer at the $\lambda_{\max }$ of MeO solution. Percent degradation (\%) was calculated using the following equation [20].

$\%$ Degradation $=\frac{\mathrm{c}_{0}-\mathrm{c}_{\mathrm{t}}}{\mathrm{c}_{\mathrm{o}}} \times 100$

When the concentration is very low, the observed rate constant, $\mathrm{k}_{\mathrm{obs}}\left(\mathrm{min}^{-1}\right)$ was determined from the simplified Langmuir-Hinshelwood model as given below [21]:

Rate $=\ln \left(C_{t} / C_{0}\right)=-k t(2)$

Where $\mathrm{k}_{\mathrm{obs}}$ is the observed rate constant in $\min ^{-1}, \mathrm{C}_{t}$ is the absorbance at a given time, $\mathrm{C}_{\mathrm{o}}$ is the absorbance at initial time and $t(\mathrm{~min})$ is the reaction time. Hence, the linear fit between $C_{t} / C_{o}$ and irradiation time demonstrates the photocatalytic degradation rate. A higher $\mathrm{k}_{\mathrm{obs}}$ value indicates a better photocatalytic activity of an investigated sample.

\subsection{Stability Taste of the As-synthesized Photocatalyst}

The recycling of the photocatalyst was performed as follows [22]: after a first photodegradation cycle of a $10 \mathrm{ppm}$ solution of methyl orange (MeO) dye using $0.15 \mathrm{~g} / \mathrm{L}$ of the as-synthesized photocatalyst and $160 \mathrm{~min}$ irradiation time, the treated solution of the dye was centrifuged for $10 \mathrm{~min}$ to settle the catalyst. The liquid phase was filtered and then the solid phase containing the photocatalyst was carefully separated for reuse. The recovered photocatalyst was washed by sufficient amount of deionized water and ethanol. Finally, the photocatalyst was dried in an oven for $12 \mathrm{~h}$ at $100^{\circ} \mathrm{C}$ before the use for next catalytic cycle and then reintroduced into fresh cycle. The process was repeated four times. The $10 \mathrm{~mL}$ suspension was withdrawn at $20 \mathrm{~min}$ time interval and centrifuged at $3000 \mathrm{rpm}$ for $10 \mathrm{~min}$. The MeO degradation and photocatalytic stability of as-synthesized photocatalyst layer was measured at the end of each cycle.

\section{Results And Discussion}

\subsection{Characterization of the As-synthesized Photocatalysts 3.1.1. XRD Analysis}

X-ray diffraction is the most powerful and successful technique commonly used for determining the structure of crystals and the arrangement of atoms within a crystal [23]. The characteristic peaks on the XRD patterns of the as-synthesized photocatalyst: $\mathrm{CeO}_{2}, \mathrm{CdS}$ and $\mathrm{CdS} / \mathrm{CeO}_{2}$ were shown in Fig. 1 . 
Accordingly, diffraction peaks observed at scattering angle observed at $2 \theta$ of $28.52,33.19,47.38,56.54$, $59.09,70.01,76.78,78.99$ and $88.24^{\circ}$ corresponding to (111), (200), (202), (311), (222), (400), (313), (402) and (422) lattice plane respectively represents the cubic fluorite structure of $\mathrm{CeO}_{2}$ [24]. The broad peaks observed at $2 \theta$ of $25.02,26.42,28.19,36.24,43.55,48.00,52.02,54.66,67.03,70.11,71.34,72.81,76.03$, 80.52 and $83.44^{\circ}$ corresponding to (100), (002), (101), (012), (110), (013), (112), (044), (023), (210), (211), (114), (212), (300) and (213) crystal plane can be ascribed to the hexagonal greenockite structure of CdS nanoparticle $[25,26]$. The broadening of the diffraction peak indicates the nanocrystalline nature of the samples and provides information about crystallite size. As the width increases, the particle size decreases and vice versa [27].

In the case of $\mathrm{CdS} / \mathrm{CeO}_{2}$ binary system, most of the diffraction peaks observed could be ascribed to cubic fluorite structure of $\mathrm{CeO}_{2}$ nanoparticle. However, diffraction peaks at $2 \theta$ values of $26.82,44.01$ and $52.21^{\circ}$ indicate the presence of hexagonal greenockite structure of CdS in the binary system $[15,19]$. No other phases can be observed in the XRD patterns of $\mathrm{CdS} / \mathrm{CeO}_{2}$ nanocomposite, suggesting that no impurity exists in the sample. It is found that the diffraction peaks for both $\mathrm{CeO}_{2}$ and $\mathrm{CdS}$ can be observed from the XRD pattern of the composite, indicating the formation of $\mathrm{CdS} / \mathrm{CeO}_{2}$ composite. The absence of other peaks in the XRD pattern of core/shell composite implies that it only consists of $\mathrm{CeO}_{2}$ and CdS.

The average crystallite size of each of the as-synthesized photocatalyst was calculated using the DebyeScherrer formula [28];

$D=\frac{\kappa \lambda}{\beta \cos \theta}$

Where, $D=$ crystallite size in $n m, K=$ the shape factor constant taken as $0.9 ; \beta$ is the full width at half maximum (FWHM) in radians, $\lambda$ is the wavelength of the X-ray $(0.15406 \mathrm{~nm})$ for Cu target Ka1 radiation and $\theta$ is the Bragg's angle. Generally the calculated average crystalline size of the as-synthesized photocatalyst confirms the involvement of good crystalline nano range between 10 and $50 \mathrm{~nm}$ [29] as summarized in Table 1.

Table 1

Crystal size of the as-synthesized photocatalysts

\begin{tabular}{|llll|}
\hline Photocatalyst & $\mathbf{2 \theta}$ (degree) & $\boldsymbol{\beta}$ (radians) & $\boldsymbol{D}(\mathbf{n m})$ \\
\hline $\mathrm{CeO}_{2}$ & 28.52 & 0.02804 & 18.406 \\
\hline $\mathrm{CdS}$ & 43.55 & 0.02338 & 23.576 \\
\hline $\mathrm{CdS} / \mathrm{CeO}_{2}(1: 1)$ & 28.61 & 0.01004 & 47.992 \\
\hline
\end{tabular}

\subsubsection{Determination of Surface Area (BET)}


Surface area of the as-synthesized nanocomposite was determined by the Brunauer-Emmett-Teller (BET) method. Table 2 shows the specific surface area of each sample investigated by nitrogen adsorptiondesorption isotherm analysis. The specific surface area is largest for $\mathrm{CeO}_{2}\left(77 \mathrm{~m}^{2} \mathrm{~g}^{-1}\right)$ whereas lowest for $\mathrm{Ag}_{3} \mathrm{PO}_{4}\left(0.122 \mathrm{~m}^{2} \mathrm{~g}^{-1}\right)$ showing the compacted nature of the later.

As indicated in Table 2, the specific surface area can be calculated and those of single and binary nanocomposite which is about 43.8627, 44.3277, 43.5162, 17.4935 and $37.6739 \mathrm{~m}^{2} \mathrm{~g}^{-1}$ for the obtained $\mathrm{CdS} / \mathrm{CeO}_{2}$ (1:0.5), $\mathrm{CdS} / \mathrm{CeO}_{2}(1: 1), \mathrm{CdS} / \mathrm{CeO}_{2}(0.5: 1)$, $\mathrm{CdS}$ and $\mathrm{CeO}_{2}$ samples, respectively. The $\mathrm{CdS} / \mathrm{CeO}_{2}$ (1:1) composite has the largest specific surface area may be because the modification of $\mathrm{CeO}_{2}$ can increase the dispersion of the $\mathrm{CdS}$ nanoparticle, as well as because the $\mathrm{CeO}_{2}$ nanoparticles have relatively large surface area. It is expected that this can facilitate enhancing adsorption of reactant molecules and, thereby, the enhanced photocatalytic activity [30].

Table 2

Specific surface area of the as-synthesized photocatalysts

\begin{tabular}{|ll|}
\hline As-synthesized photocatalyst & BET surface area $\left(\mathbf{m}^{\mathbf{2}} \mathbf{g}^{-1}\right)$ \\
\hline $\mathrm{CeO}_{2}$ & $37.6739 \pm 0.1923$ \\
\hline $\mathrm{CdS}$ & $17.4935 \pm 0.0745$ \\
\hline $\mathrm{CdS} / \mathrm{CeO}_{2}(1: 0.5)$ & $43.8627 \pm 0.7335$ \\
\hline $\mathrm{CdS} / \mathrm{CeO}_{2}(1: 1)$ & $44.3277 \pm 0.0012$ \\
\hline $\mathrm{CdS} / \mathrm{CeO}_{2}(0.5: 1)$ & $43.5162 \pm 0.1108$ \\
\hline
\end{tabular}

\subsubsection{SEM-EDX Image Study}

Morphological images of the as-synthesized photocatalysts; $\mathrm{CeO}_{2}, \mathrm{CdS}$ and $\mathrm{CdS} / \mathrm{CeO}_{2}$ were investigated as shown in Fig. 2a-c respectively.

The EDX spectrum shows the presence of all the relevant components in each photocatalyst. According to the SEM images shown in Fig. 2a, the morphology of $\mathrm{CeO}_{2}$ nanoparticle is observed to be nearly spherical with slight agglomeration (single phase). From the SEM image shown in Fig. $2 \mathrm{~b}$ it is noticed that the surface morphologies are in the form of assemblies of CdS nanoparticles and uniformly distributed over the entire surface. The EDX spectrum and elemental mapping shows that the CdS nanoparticle contains average stoichiometric composition with $80.45 \%$ of cadmium and $19.55 \%$ of sulphur. As can be seen from Fig. $2 \mathrm{c}$, the $\mathrm{CdS} / \mathrm{CeO}_{2}$ composite also exhibited no distinct morphology, though cubic like structures appeared rarely. On the other hand, the percent chemical distribution gradients across the surface of the sample ( $\mathrm{w} / \mathrm{w} \%)$ were determined from results of energy dispersive Xray (EDX) analysis. Elemental composition (weight \%) of the $\mathrm{CdS} / \mathrm{CeO}_{2}$ photocatalysts contains average stoichiometric composition with $24.85 \%$ of cerium, $62.5 \%$ of cadmium and $12 \%$ of sulphur. Interestingly, 
EDX spectrum result exhibits the presence of $\mathrm{Ce}, \mathrm{Cd}$ and $\mathrm{S}$ peaks indicating the $\mathrm{CeO}_{2}$ and $\mathrm{CdS}$ nanoparticles [17].

\subsubsection{UV/Vis Diffuse Absorption Spectra of the As- synthesized Photocatalysts}

UV/Vis diffuse absorption edges of the as-synthesized photocatalysts are obtained from plot of absorbance against wavelength.

The intercept of the tangent line on descending part of the absorption peak at the wavelength axis gives the value of diffuse absorption edge ( $\mathrm{nm}$ ). In such case band gap energy (Eg) of the as-synthesized photocatalysts was obtained from Eq. 4 [31].

$\mathrm{Eg}=\frac{1240 \mathrm{eV}}{\lambda_{\max }}$

Where, Eg is bandgap energy in electron volts and $\lambda_{\max }$ is wavelength $(\mathrm{nm})$ corresponding to absorption edge.

But estimating the band gap using the above approach sometimes may not provide clear tangential line when the peak is not well resolved for the samples. To avoid the difficulties in obtaining band gap energy from UV/Vis absorption spectroscopy in dispersed samples, diffuse reflectance measurements of dry powders can be performed. The optical absorption properties of each of the as-synthesized photocatalyst were investigated by using a UV/Vis diffuse reflectance spectrometer in the range of 200-900 nm. The band gap values of the photocatalysts were determined by analyzing the optical data with the expression for the optical absorbance $a$ and the photon energy hv using Tauc's plot $[32,33,34]$.

ahv $=A(h v-E g)^{n / 2}(5)$

where $\mathrm{a}$ is the absorption coefficient, which is proportional to the absorbance, $\mathrm{h}$ is the Planck's constant (J.s), $v$ is the light frequency $\left(\mathrm{s}^{-1}\right), \mathrm{A}$ is the absorption constant, Eg the band gap energy and $\mathrm{n}$ is a constant related to the electronic interband transition. $\mathrm{n}=2$ for an indirect allowed transition (plotted as $(\mathrm{ahv})^{1 / 2}$ versus $\mathrm{Eg}$ ), $\mathrm{n}=3$ for an indirect forbidden transition (plotted as (ahv) ${ }^{1 / 3}$ versus Eg), $\mathrm{n}=1 / 2$ for a direct allowed transition (plotted as $(\mathrm{ahv})^{2}$ versus Eg), $n=3 / 2$ for a direct forbidden transition [plotted as $(a h v)^{2 / 3}$ versus Eg] [35]. The band gaps was then determined by extrapolating the straight line portion of the $(\mathrm{ahv})^{2}$ versus (hv) graphs to the (hv) axis until (ahv) ${ }^{1 / n}=0$ the linear section of this spectra as shown in the Fig. 3.

The absorption edges of the binary $\left(\mathrm{CdS} / \mathrm{CeO}_{2}\right)$ photocatalysts are well extended to visible regions of spectrum as compared to the single nanoparticles.

This may be due to the effect of modification in the electronic levels of each single nanoparticle by making them binary composite. 
Based on Tauc's plot as Eq. (5) the band gaps for all the as-synthesized materials were displayed in Table 3. The calculated band gaps of the single systems: $\mathrm{CeO}_{2}$ and $\mathrm{CdS}$ are found to be $3.26 \mathrm{eV}$ and $2.48 \mathrm{eV}$ respectively. These findings are similar with previous reports made on these nanoparticles [17, 19, 36, 37]. The binary systems $\mathrm{CdS} / \mathrm{CeO}_{2}$ (molar ratio: 1:0.5, 1:1 and 0.5:1) have band gaps of $2.27 \mathrm{eV}, 2.23 \mathrm{eV}$ and $2.29 \mathrm{eV}$ respectively. This finding also similar to previous reports made on the same nanoparticles $[15,17$, 19].

Table 3

Maximum wavelength and band gap energy (Eg) of the as-synthesized photocatalysts

\begin{tabular}{|c|c|c|}
\hline & \\
\hline As-synthesized photocatalyst & Max. Wavelength & Band gap (Eg) eV \\
\hline $\mathrm{CeO}_{2}$ & 380 & 3.26 \\
\hline CdS & 500 & 2.48 \\
\hline $\mathrm{CdS} / \mathrm{CeO}_{2}(1: 0.5)$ & 546 & 2.27 \\
\hline $\mathrm{CdS} / \mathrm{CeO}_{2}(0.5: 1)$ & 542 & 2.29 \\
\hline $\mathrm{CdS} / \mathrm{CeO}_{2}(1: 1)$ & 555 & 2.23 \\
\hline
\end{tabular}

The FTIR spectrum in the mid-infrared region is the feature of a particular compound that gives the information about the functional groups, molecular geometry and intra/intermolecular interactions. Both inorganic and organic materials can be analyzed in the spectrum.

From the as-synthesized photocatalyst, the functional groups of $\mathrm{CeO}_{2}$ were analyzed by FTIR in the range from 400 to $4000 \mathrm{~cm}^{-1}$ and displayed in Fig. 4. In case of $\mathrm{CeO}_{2}$, the band at 3435 and $1620 \mathrm{~cm}^{-1}$ corresponds to the $\mathrm{O}-\mathrm{H}$ stretching vibration and $-\mathrm{OH}$ scissor bending mode respectively, which is originated from physical absorbed ( $\mathrm{H}$-bonded) water molecules or surface-OH groups [38, 39]. The band located around $1047 \mathrm{~cm}^{-1}$ has been attributed to the $\mathrm{C}-0$ stretching vibration may be from the additional $\mathrm{CO}_{2}$ that was absorbed at $\mathrm{CeO}_{2}$ surface [40]. The wide band at $1315 \mathrm{~cm}^{-1}$ consists of the symmetrical stretching mode of $\mathrm{N}=\mathrm{O}$ and the inside bending mode of $\mathrm{N}-\mathrm{H}$. The peak at $850 \mathrm{~cm}^{-1}$ attributed to outside bending mode of $\mathrm{N}-\mathrm{H}[41,42]$.

The peaks observed at $1387 \mathrm{~cm}^{-1}$ could be ascribed to the stretching vibration of $\mathrm{N}-\mathrm{O}$ nitrate groups $\left(\mathrm{NO}_{3}{ }^{-}\right)$which resulted from a precursor solution of $\mathrm{Ce}\left(\mathrm{NO}_{3}\right)_{3} \cdot 6 \mathrm{H}_{2} \mathrm{O}$ that was used to synthesis the nanoparticle $\left(\mathrm{CeO}_{2}\right)$ [43]. The intense band at $521 \mathrm{~cm}^{-1}$ corresponds to the $\mathrm{Ce}-\mathrm{O}$ stretching vibration [17, 44].

\subsubsection{Photoluminescence (PL) Study of the As-synthesized Photocatalysts}


$\mathrm{PL}$ is mainly used as a diagnostic and development tool in semiconductor research, since it can provide information about the electronic structure and the emission mechanism of the material [45]. The PL emission spectra of different photocatalysts $\left(\mathrm{CeO}_{2}, \mathrm{CdS}\right.$ and $\mathrm{CdS} / \mathrm{CeO}_{2}$ (in 0.5:1, 1:1 and 1:0.5 molar ratios) were determined. The order of intensity is $\mathrm{CeO}_{2}>\mathrm{CdS}>\mathrm{CdS} / \mathrm{CeO}_{2}(0.5: 1)>\mathrm{CdS} / \mathrm{CeO}_{2}$ (1:0.5) $>$ $\mathrm{CdS} / \mathrm{CeO}_{2}(1: 1)$ as indicated in the Fig. 5 .

In binary nanocomposite the photoinduced electrons and holes can be effectively separated and hence excitation PL intensity goes down. This is because, lower the excitation PL intensity, stronger the capacity of coupled materials to capture photoinduced electrons, higher the separation rate of photoinduced electrons and holes, and higher the photocatalytic activity [46]. So, in this study it was clearly observed that the lower $\mathrm{PL}$ emission spectra were recorded for $\mathrm{CdS} / \mathrm{CeO}_{2}(1: 1)$ nanocomposite.

This might be also due to the photogenerated electron hole pair in $\mathrm{CeO}_{2}$ separated well due to the synergy effect of coupling of A-type heterojunction $\left(\mathrm{CdS} / \mathrm{CeO}_{2}\right)$. In general the PL intensities of single systems were found to be higher than the binary system photocatalyst.

\subsection{Photocatalytic Studies}

\subsubsection{Photocatalytic Activities of the As-synthesized Photocatalysts}

Methyl orange (MeO), with a characteristic absorption at $464 \mathrm{~nm}$ is chosen as a typical organic pollutant for testing the photocatalytic activity of the as-prepared products. The photocatalytic activities of all the as-synthesized sample were evaluated by testing their ability in the degradation of $\mathrm{MeO}$ (initial dye concentration of $10 \mathrm{ppm}$ and catalyst load of $0.2 \mathrm{~g} / \mathrm{L}$ ) under $160 \mathrm{~min}$ visible irradiation time. The degradation rate was analyzed by plotting $C_{t} / C_{o}$ versus irradiation time. The results show that the characteristic absorption peaks corresponding to $\mathrm{MeO}$ decrease rapidly as the exposure time increases, indicating the decomposition of $\mathrm{MeO}$ and the significant reduction in the $\mathrm{MeO}$ concentration.

The photocatalytic performance of $\mathrm{CeO}_{2}, \mathrm{CdS}$ and $\mathrm{CdS} / \mathrm{CeO}_{2}$ (in $0.5: 1,1: 1$ and 1:0.5 molar ratios) photocatalyst was first evaluated by the degradation of model pollutant $\mathrm{MeO}$ under visible light irradiation. Before the photocatalytic reaction, an adsorption step in dark conditions was allowed to take place during $60 \mathrm{~min}$. The result indicates that the adsorption capacity of binary and single photocatalyst become in the order of $\mathrm{CeO}_{2}<\mathrm{CdS}<\mathrm{CdS} / \mathrm{CeO}_{2}(0.5: 1)<\mathrm{CdS} / \mathrm{CeO}_{2}(1: 0.5)<\mathrm{CdS} / \mathrm{CeO}_{2}(1: 1)$. The photocatalytic activities of pure $\mathrm{CeO}_{2}$ and $\mathrm{CdS}$ were lower than that of the composite photocatalyst. They decolorized $18.58,27.07,32.06,35.98$ and $53.73 \%$ of $\mathrm{MeO}$ in 160 min of irradiation time respectively. The photocatalytic activities of pure $\mathrm{CeO}_{2}$ are lower than $\mathrm{CdS}$ due to its higher band gap energy which makes it less sensitive to visible irradiation unlike other single counterparts [47].

The increment of photocatalytic degradation efficiency of $\mathrm{CdS}$ from that of $\mathrm{CeO}_{2}$ over $\mathrm{MeO}$ solution is due to the efficient charge separation, narrow band gap that makes it sensitive to visible portion of the 
spectrum, less electron-hole recombination, and a wide range of optical absorption of light by the composite could be possible reasons for the enhanced photoactivity [36]. In the A-type heterojunction system $\mathrm{CdS} / \mathrm{CeO}_{2}(1: 1)$, the increased photocatalytic activities of $\mathrm{CeO}_{2}$ could be initiated by conduction band electrons of CdS that involve in the photoreduction process [26].

There are many reports available on the photocatalytic degradation efficiency of binary nanocomposite (A-type) over different azo dyes (MeO). For A-type heterojunction, $\mathrm{CdS} / \mathrm{CeO}_{2}, \mathrm{CdS} / \mathrm{ZnO}$ and $\mathrm{CdS} / \mathrm{TiO}_{2}$ also shows percent decolorization about $38.00,49.30$ and $55.00 \%$ over methyl orange dye respectively in different irradiation time $[17,48,49]$. In our case $53.73 \%$ for A-type heterojunction in 160 min irradiation time which is partially in line with the previous reports on both heterojunction.

The kinetics of the photocatalytic degradation was also exhibited using the pseudo-first-order reaction [50]. The rate constant of the binary $\mathrm{CdS} / \mathrm{CeO}_{2}(1: 1)$ nanocomposite was higher than single and binary in other ratio photocatalysts, indicating the presence of a synergistic effect as indicated in Table 4 . Among them, the apparent rate constants of $\mathrm{CdS} / \mathrm{CeO}_{2}(1: 1)$ was the highest, calculated based on the equation $\ln \left(C_{t} / C_{o}\right)$ per irradiation time, and it was almost $18,12,8.9$ and 6.13 times higher than that of $\mathrm{CeO}_{2}, \mathrm{CdS}$, $\mathrm{CdS} / \mathrm{CeO}_{2}(0.5: 1)$ and $\mathrm{CdS} / \mathrm{CeO}_{2}(1: 0.5)$ respectively.

Table 4

The apparent rate constants and \% degradation of the as-synthesized photocatalysts after $160 \mathrm{~min}$

\begin{tabular}{|lll|}
\hline As-synthesized photocatalyst & Degradation $(\%)$ & Rate constant, $\mathbf{k}\left(\times 10^{-4} \mathbf{~ m i n}^{-1}\right)$ \\
\hline $\mathrm{CeO}_{2}$ & 18.58 & 9.006 \\
\hline $\mathrm{CdS}$ & 27.07 & 55.210 \\
\hline $\mathrm{CdS} / \mathrm{CeO}_{2}(1: 1)$ & 53.73 & 162.11 \\
\hline $\mathrm{CdS} / \mathrm{CeO}_{2}(0.5: 1)$ & 32.06 & 80.150 \\
$\mathrm{CdS} / \mathrm{CeO}_{2}(1: 0.5)$ & 35.98 & 108.072 \\
\hline
\end{tabular}

\subsection{Photocatalytic Stability of the As-synthesized Photocatalyst}

In addition to photocatalytic efficiency, the stability of photocatalyst is also very important for practical application. To evaluate the stability of photocatalytic performance of binary $\mathrm{CdS} / \mathrm{CeO}_{2}(1: 1)$, the circulating run in the photocatalytic degradation of $\mathrm{MeO}$ was carried out under visible light irradiation. The process was repeated up to four times. As exhibited in Fig. 7 the studies revealed that the composite demonstrated moderate stability after recovery. 
In the first cycle $53.16 \%$ of the dye was degraded after $160 \mathrm{~min}$ of irradiation time. Subsequently the second, third and fourth cycle degraded $38.71,23.17$ and $17.41 \%$ of the dye corresponding to the rate constant (k) from 0.00493 to $0.00310,0.00201$ and $0.00120 \mathrm{~min}^{-1}$ respectively. Agglomeration and sedimentation of the dye around the composite particles after each cycle of photocatalytic degradation is a possible cause of the observed decrease on the degradation rate, because each time the photocatalyst is reused new parts of the photocatalyst surface become unavailable for dye adsorption and thus photon absorption, reducing the efficiency of the catalytic reaction [51, 52]. Besides, one might expect a loss in the photocatalyst during recycling which eventually affect catalytic activity after each cycle.

This decreases the degradation rate of the as-synthesized photocatalyst may be due to the weakening of the absorbance ability of the catalyst or the loss of some catalyst during the cycling reaction. The result demonstrates that $\mathrm{CdS} / \mathrm{CeO}_{2}(1: 1)$ nanocomposite shows a good photocatalytic performance as well as moderate stability after 4 cycles in 160 min.

\subsection{General Proposed Mechanism of degradation of $\mathrm{MeO}$ Using $\mathrm{CdS} / \mathrm{CeO}_{2}$}

According to the above experimental research, a probable mechanism of charge transfer and photocatalytic degradation of organic pollutant methyl orange $(\mathrm{MeO})$ over the $\mathrm{CdS} / \mathrm{CeO}_{2}$ nanocomposite under visible light irradiation is put forward and illustrated in Fig. 8. The light illumination on $\mathrm{CdS} / \mathrm{CeO}_{2}$ nanocomposite causes the generation of electron $\left(\mathrm{e}^{-}\right)$in conduction band (CB) and holes $\left(\mathrm{h}^{+}\right)$in the valence band (VB).

Under visible light irradiation, the CdS can be activated, and the photoinduced electrons at the conduction band of $\mathrm{CdS}$ are transferred to the conduction band of $\mathrm{CeO}_{2}$. The electrons will then react with water to produce hydrogen. On the other hand, the photoexcited holes at the valence band of CdS nanoparticles are captured by the $\mathrm{MeO}$ dye.

At CB site, molecular oxygen $\left(\mathrm{O}_{2}\right)$ forms superoxide radical $\cdot \mathrm{O}_{2}{ }^{-}$in the presence of the photoexcited $\mathrm{CB} \mathrm{e}^{-}$ and subsequently reacts with $\mathrm{H}^{+}$to form $\mathrm{HO}_{2}$. radical species. During the $\mathrm{e}^{-}$transfer from $\mathrm{CdS}$ to $\mathrm{CB}$ of $\mathrm{CeO}_{2}$, the generated photoinduced $\mathrm{h}^{+}$in VB might react with water $\left(\mathrm{H}_{2} \mathrm{O}\right)$ and the adsorbed $\mathrm{MeO}$ dye molecule to yield hydroxyl radical $(\cdot \mathrm{OH})$ and $\mathrm{MeO} \cdot{ }^{-}$anions radical respectively [53]. On the other hand, electrons in the $\mathrm{CeO}_{2} \mathrm{CB}$ can migrate to its $\mathrm{VB}$, while the holes generated in the $\mathrm{CeO}_{2}$ VB move to CdS VB surface [54]. It is known that these oxygenous radicals $\left(\cdot \mathrm{O}_{2}{ }^{-}, \cdot \mathrm{OH}\right.$ and $\left.\mathrm{HO}_{2}{ }^{\circ}\right)$ act as potential oxidizing and reducing species for the degradation of organic molecules $(\mathrm{MeO})$ [55]. The proposed photoreaction mechanism of $\mathrm{CdS} / \mathrm{CeO}_{2}$ composite over $\mathrm{MeO}$ degradation under visible light follows:

$\mathrm{CdS} / \mathrm{CeO}_{2}+\mathrm{hv} \rightarrow \mathrm{h}^{+}{ }_{\mathrm{VB}}+\mathrm{e}_{\mathrm{CB}}^{-}(6)$

\section{Oxidative reaction}


$\mathrm{h}^{+} \mathrm{VB}^{+}+\mathrm{H}_{2} \mathrm{O} \rightarrow \mathrm{H}^{+}+\cdot \mathrm{OH}(7)$

$\cdot \mathrm{OH}+\mathrm{MeO} \rightarrow$ (Intermediates) $\rightarrow \mathrm{CO}_{2}+\mathrm{H}_{2} \mathrm{O}$

\section{Reductive reaction}

$\mathrm{e}^{-}{ }_{\mathrm{CB}}+\mathrm{O}_{2} \rightarrow \cdot \mathrm{O}_{2}^{-}(8)$

$\cdot \mathrm{O}_{2}{ }^{-}+\mathrm{MeO} \rightarrow($ Intermediates $) \rightarrow \mathrm{CO}_{2}+\mathrm{H}_{2} \mathrm{O}$

\section{Generally:}

$\cdot \mathrm{O}_{2}^{-}\left(\cdot \mathrm{OH}, \mathrm{h}^{+}\right)+\mathrm{MeO}+\mathrm{O}_{2} / \mathrm{H}_{2} \mathrm{O} \rightarrow$ Degradation products (9)

In our case, on comparison with single and binary photocatalysts, the superior photocatalytic activity of binary nanocomposite under visible light might result from the enhanced charge separation and the formation of more active radicals $\left(\cdot \mathrm{O}_{2}{ }^{-}\right.$and $\left.\cdot \mathrm{OH}\right)$ which are induced by the synergetic effect between $\mathrm{CdS}$ and $\mathrm{CeO}_{2}$. As a result, $\mathrm{CdS} / \mathrm{CeO}_{2}$ nanocomposite delivers high photogenerated $\mathrm{e}^{-}-\mathrm{h}^{+}$pair charge separation and produces sufficiently high amount of radicals for the high degradation of $\mathrm{MeO}$ dye under visible light irradiation. The photocatalytic performance of the photocatalyst mainly depends on: (i) its light absorption properties; (ii) the rates of reduction and oxidation on the surface of the catalyst by the electrons and holes; and (iii) the electron-hole recombination rate [56].

\section{Declarations}

\section{Declaration of Competing Interest}

This manuscript entitled with "Synthesis and Characterization of $\mathrm{CdS} / \mathrm{CeO}_{2}$ Nanocomposite with Improved Visible-Light Photocatalytic Degradation of Methyl Orange Dye" consists of 3 tables and 8 figures. It has not been published previously; it is not under consideration for publication elsewhere. If accepted, it will not be published elsewhere in the same form, in English or in any other language.

\section{References}

1. Akpan, U. and Hameed, B. 2009. Parameters affecting the photocatalytic degradation of dyes using $\mathrm{TiO}_{2}$ based photocatalysts. Journal of Hazardous Materials, 170: 520-529.

2. Jalil, A.A., Adam, S.H., Rahim, N.D., Arif, M., Aziz, A., Hanis, N., Hairom, H. and Khairul, N.M. 2010. Adsorption of methyl orange from aqueous solution onto calcined Lapindo volcanic mud. Journal of Hazardous Materials, 181: 755-762.

3. Sharma, V., Kakodia, A., Sharma, B., Pamecha, S. and Khandelwal, R. 2013. Photocatalytic degradation of Brilliant Blue-R by $\mathrm{ZnO}$ in aqueous media. International Journal of Green and Herbal 
Chemistry, 2(3): 730-736.

4. Kansal, S., Kaur, N. and Singh, S. 2009. Photocatalytic degradation of two commercial reactive dyes using nano photocatalysts. Nanoscale Research Letters, 4: 709-716.

5. Prabha, I. and Lathasree, S. 2013. Photocatalytic performance of nanocatalyst for the effective removal of dye in the wastewater. Chemical Science Transactions, 2(1): 220-224.

6. Ullah, I., Ali, S., Hanif, M. and Shahid, S. 2012. Nanoscience for environmental remediation: A Review. International Journal of Chemical and Biochemical Sciences, 2: 60-77.

7. Yuhas, B.D., Smeigh, A.L., Douvalis, A.P., Wasielewski, M.R. and Kanatzidis, M.G. 2012. Photocatalytic Hydrogen evolution from FeMoS-Based biomimetic Chalcogels. Journal of American Chemical Society, 134(25): 10353-10356.

8. Lu, X., Zhai, T., Cui, H., Shi, J., Xie, S., Huang, Y., Liang, C. and Tong, Y. 2011. Redox cycles promoting photocatalytic hydrogen evolution of $\mathrm{CeO}_{2}$ nanorods. Journals of Material Chemistry, 21(15): 55695572.

9. Zhang, J., Li, L., Huang, X. and Li, G. 2012. Fabrication of Ag-CeO $\mathrm{C}_{2}$ core-shell nanospheres with enhanced catalytic performance due to strengthening of the interfacial interactions. Journal of Material Chemistry, 22(21): 10480-10487.

10. Reddy, B.M., Lakshmanan, P. and Khan, A. 2004. Investigation of surface structures of dispersed $\mathrm{V}_{2} \mathrm{O}_{5}$ on $\mathrm{CeO}_{2}-\mathrm{SiO}_{2}, \mathrm{CeO}_{2}-\mathrm{TiO}_{2}$ and $\mathrm{CeO}_{2}-\mathrm{ZrO}_{2}$ mixed oxides by XRD, Raman, and XPS techniques. Journal of Physical Chemistry B, 108 (43): 16855-16863.

11. Camino, D., Deroo, D., Salardenne, J. and Treuil, N. 1995. $\left(\mathrm{CeO}_{2}\right)\left(\mathrm{TiO}_{2}\right) 1-\chi$ counters electrode materials for lithium electrochromic devices. Solar Energy Materials and Solar Cells, 39: 349-366.

12. Yoon, K.H., Cho, J. and Kang, D.H. 1999. Physical and photoelectrochemical properties of the $\mathrm{TiO}_{2} / \mathrm{ZnO}$ system. Materials Research Bulletin, 34(9): 1451-1461.

13. Reddy, B.M., Khan, A., Lakshmanan, P., Aouine, M., Loridant, S. and Volta, J.C. 2005. Structural characterization of nanosized $\mathrm{CeO}_{2}-\mathrm{SiO}_{2}, \mathrm{CeO}_{2}-\mathrm{TiO}_{2}$, and $\mathrm{CeO}_{2}-\mathrm{ZrO}_{2}$ catalysts by XRD, Raman, and HREM techniques. Journal of Physical Chemistry B, 109 (8): 3355-3363.

14. Song, Y., Zhao, H., Chen, Z., Wang, W., Huang, L., Xu, H. and Li, H. 2016. The $\mathrm{CeO}_{2} / \mathrm{Ag}_{3} \mathrm{PO}_{4}$ photocatalyst with stability and high photocatalytic activity under visible light irradiation. Physical Status Solidi A, 213(9): 2356-2363.

15. You, D.T., Pan, B., Jiang, F., Zhou, Y.G. and Su, W.Y. 2016. CdS nanoparticles $/ \mathrm{CeO}_{2}$ nanorods composite with high-efficiency visible-light-driven photocatalytic activity. Applied Surface Science, 363: 154-160.

16. Gogoi, A. and Sarma, C.K. 2017. Synthesis of the novel $\beta$-cyclodextrin supported $\mathrm{CeO}_{2}$ nanoparticles for the catalytic degradation of methylene blue in aqueous suspension. Materials Chemistry and Physics, 194: 327-336.

17. Abi M. Taddesse., Tigabu Bekele., Isabel Diaz. and Abebaw Adgo. 2021. Polyaniline supported $\mathrm{CdS} / \mathrm{CeO}_{2} / \mathrm{Ag}_{3} \mathrm{PO}_{4}$ nanocomposite: $\mathrm{An}$ "A-B" type tandem n-n heterojunctions with enhanced 
photocatalytic activity. Journal of Photochemistry and Photobiology, A: Chemistry, 406: 113005.

18. Singh, V., Sharma, P. and Chauhan, P. 2011. Synthesis of CdS nanoparticles with enhanced optical properties. Material Characterization, 62(1): 43-52.

19. ljaz, S., Ehsan, M.F., Ashiq, M.N., Karamat, N. and He, T. 2016. Preparation of $\mathrm{CdS} / \mathrm{CeO}_{2}$ core/shell composite for photocatalytic reduction of $\mathrm{CO}_{2}$ under visible-light irradiation. Applied Surface Science, 390: 550-559

20. Hong, R.Y., Li, J.H., Chen, L.L., Liu, D.Q., Li, H.Z., Zheng, Y. and Ding, J. 2009. Synthesis, surface modification and photocatalytic property of ZnO nanoparticles. Journal of Powder Technology, 189: 426-432.

21. Liu, B., Zhao, X., Terashima, C., Fujishima, A. and Nakata, K. 2014. Thermodynamic and kinetic analysis of heterogeneous photocatalysis for semiconductor systems. Physical Chemistry Chemical Physics, 16: 8751-8760.

22. Saggioro, E.M., Oliveira, A.S., Pavesi, T., Maia, C.G., Ferreira, L.F.V. and Moreira, J.C. 2011. Use of titanium dioxide photocatalysis on the remediation of model textile wastewaters containing Azo dyes. Molecules, 16: 10370-10386.

23. Leng, Y. 2008. Materials characterization: Introduction to microscopic and spectroscopic methods, John Wiley and Sons (Asia) Pte Ltd.

24. Roggenbuck, J., Schaer, H., Tsoncheva, T., Minchev, C., Hanss, J. and Tiemann, M. 2007. Mesoporous $\mathrm{CeO}_{2}$ : Synthesis by nanocasting, characterization and catalytic properties. Microporous and Mesoporous Materials, 101: 335-341.

25. Hernandez-Gordillo, A., Romero, A.G., Tzompantzi, F. and Gomez, R. 2013. New nanostructured CdS fibers for the photocatalytic reduction of 4-nitrophenol. Powder Technology, 250: 97-102.

26. Zhang, X., Zhang, N., Xu, Y. and Tang, Z.R. 2015. One-dimensional CdS nanowires $\mathrm{CeO}_{2}$ nanoparticles composites with boosted photocatalytic activity. New Journal of Chemistry, 39: 6756-6764.

27. Banerjee, R., Jayakrishnan, R. and Ayyub, P., 2000. Effect of the size induced structural transformation on the band gap in CdS nanoparticles. Journal of Physics: Condensed Matter, 12: 10647-10654.

28. Gupta, V., Gupta, A.R. and Kant, V. 2013. Synthesis, characterization and biomedical application of nanoparticles. Science International, 1(5): 167-174.

29. Akram, M., Kanwal, Z., Rauf, A., Sabri, N., Riaz, S. and Naseem, S. 2016. Size and shape dependent antibacterial studies of silver nanoparticles synthesized by wet chemical routes. Nanomaterials, 6 : 74-79.

30. Shen, Z., Chen, G., Yu, Y., Wang, Q., Zhou, C., Hao, L., Li, Y., He, L. and Mu, R. 2012. Sonochemistry

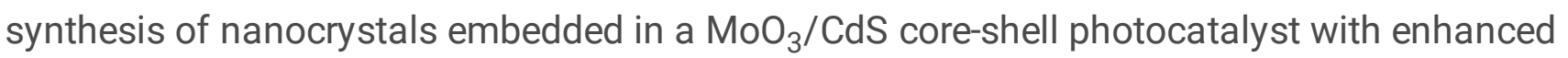
hydrogen production and photodegradation. Journal of Material Chemistry, 22: 19646-19651.

31. El-Kemary, M., El-shamy, H. and El-mahasseb, I. 2010. Photocatalytic degradation of Ciprofloxacin drug in water using ZnO nanoparticles. Journal of Luminescence, 130: 2327-2331. 
32. Kubelka, P. and Munk, F. 1931. Use of diffuse reflectance spectroscopy for optical characterization of un-supported nanostructures. Journal of Applied Physics, 12: 593-620.

33. Tauc, T. and Abeies, F. 1970. Optical properties of solids. IOP Publishing Ltd, North Holland, Amsterdam, p. 903.

34. Zou, Z., Qiu, Y., Xie, C., Xu, J., Luo, Y., Wang, C. and Yan, H. 2015. CdS/TiO 2 nanocomposite film and its enhanced photoelectric responses to dry air and formaldehyde induced by visible light at room temperature. Journal of Alloys Compound, 645: 17-23.

35. Lopez, R. and Gomez, R. 2012. Band-gap energy estimation from diffuse reflectance measurements on sol-gel and commercial $\mathrm{TiO}_{2}$ : a comparative study. Journal of Sol-Gel Science and Technology, 61: 1-7.

36. Magesh, G., Viswanathan, B., Viswanath, R. P. and Varadarajan, T. K. 2009. Photocatalytic behavior of $\mathrm{CeO}_{2}-\mathrm{TiO}_{2}$ system for the degradation of methylene blue. Indian Journal of Chemicals, 3: 480-488.

37. Umezawa, N., Shuxin, O. and Ye, J. 2011. Theoretical study of high photocatalytic performance of $\mathrm{Ag}_{3} \mathrm{PO}_{4}$. Physical Review, B. 83: 035202.

38. Dos Santos, M.L., Lima, R.C., Riccardi, C.S., Tranquilin, R.L., Bueno, P.R., Varela, J.A. and Longo, E. 2008. Preparation and characterization of ceria nanospheres by microwave- hydrothermal method. Materials Letters, 62: 4509-4511.

39. Zawadzki, M. 2008. Preparation and characterization of ceria nanoparticles by microwave- assisted solvothermal process. Journal of Alloys Compounds, 454: 347-351.

40. Khalil, K.M.S., Leena, A., Elkabee, L.A. and Murphy, B. 2005. Preparation and characterization of thermally stable porous ceria aggregates formed via a sol-gel process of ultrasonically dispersed cerium (IV) isopropoxide. Microporous and Mesoporous Materials, 78: 83-89.

41. Yu, X., Ye, P., Yang, L., Yang, S., Zhou, P. and Gao, W. 2007. Preparation of hexagonal cerium oxide nanoflakes by a surfactant free route and its optical property. Journal of Material Research, 22: 30063013.

42. Prekajski, M., Fruth, V., Andronescu, C., Trandafilovic, L.V., Pantic, J., Kremenovic, A. and Matovic, B. 2013. Thermal stability of $\mathrm{Ce}_{1-\mathrm{x}} \mathrm{Bi}_{\mathrm{x}} \mathrm{O}_{2-}(\mathrm{x}=0.1-0.5)$ solid solution. Journal of Alloys and Compounds, 578: 26-31.

43. Salimi, F., Abdollahifar, M., Jafari, P. and Hidaryan, M. 2017. A new approach to synthesis and growth of AlOOH nanocrystalline with high pore volume. Journal of Serbia Chemical Society, 82: 1-11.

44. Ho, C., Yu, J.C., Kwong, T., Mak, A.C. and Lai, S. 2005. Morphology controllable synthesis of mesoporous $\mathrm{CeO}_{2}$ nano and microstructures. Chemical Materials, 17: 4514-4522.

45. Lefebvre, J., Austing, D.G., Bond, J. and Finnie, P. 2006. Photoluminescence imaging of suspended single-walled carbon nanotubes. Nano Letters, 6: 1603-1608.

46. Katsumata, H., Hayashi, T., Taniguchi, M., Suzuki, T. and Kaneco, S. 2014. Highly efficient visible light driven $\mathrm{AgBr} / \mathrm{Ag}_{3} \mathrm{PO}_{4}$ hybrid photocatalysts with enhanced photocatalytic activity. Materials Science in Semiconductor Processing, 25: 68-75. 
47. Ji, P., Zhang, J., Chen, F. and Anpo, M. 2009. Study of adsorption and degradation of Acid Orange 7 on the surface of $\mathrm{CeO}_{2}$ under visible light irradiation. Applied Catalysis B, 85(3-4), 148-154.

48. Gezahegn Geresu. 2017. Polyaniline supported $\mathrm{CdS} / \mathrm{ZnO} / \mathrm{Ag}_{3} \mathrm{PO}_{4}$ nanocomposite: synthesis and characterization for photocatalytic activity and antimicrobial applications. MSc Thesis, Haramaya University, Haramaya, Ethiopia.

49. Zhou, P., Le, Z., Xie, Y., Fang, J. and Xu, J. 2017. Studies on facile synthesis and properties of mesoporous $\mathrm{CdS} / \mathrm{TiO}_{2}$ composite for photocatalysis applications. Journal of Alloys and Compounds, 692: 170-177.

50. Ren, J., Chai, Y., Liu, Q., Zhang, L. and Dai, W.L. 2017. Intercorrelated $\mathrm{Ag}_{3} \mathrm{PO}_{4}$ nanoparticles decorated with graphic carbon nitride: Enhanced stability and photocatalytic activities for water treatment. Applied Surface Science, 403: 177-186.

51. Wang, P., Huang, B., Qin, X., Zhang, X., Dai, Y., Wei, J. and Whangbo, M.H. 2008. Ag/AgCl: a highly efficient and stable photocatalyst active under visible light. Angewandte Chemie International Edition, 47: 7931-7933.

52. Zhang, W., Hu, C., Zhai, W., Wang, Z., Sun, Y., Chi, F., Ran, S., Liu, X. and Lv, Y. 2016. Novel $\mathrm{Ag}_{3} \mathrm{PO}_{4} / \mathrm{CeO}_{2} \mathrm{p}$-n hierarchical heterojunction with enhanced photocatalytic performance. Materials Research, 19(3): 673-679.

53. Fujishima, A., Rao, T.N. and Tryk, D.K. 2000. Titanium dioxide photocatalysis. Journal of Photochemistry and Photobiology C: Photochemistry Reviews, 1(1): 1-21.

54. Hidalgo, D., Bocchini, S., Fontana, M., Saraccob, G. and Hernandez, S. 2015. Green and low-cost synthesis of $\mathrm{PANI}^{-\mathrm{TiO}_{2}}$ nanocomposite mesoporous films for photoelectrochemical water splitting. Royal Society of Chemistry, 5: 49429-49438.

55. Ameen, A., Akhtar, M.S., Kim, Y.S., Yang, B. and Shin, H.S. 2011. An effective nanocomposite of polyaniline and ZnO: preparation, characterizations, and its photocatalytic activity. Colloid Polymer Sciences, 289: 415-421.

56. Li, J., Zhu, L., Wu, Y., Harima, Y., Zhang, A. and Tang, H. 2006. Green and low-cost synthesis of $\mathrm{PANI} / \mathrm{TiO}_{2}$ nanocomposite mesoporous films for photoelectrochemical water splitting. Polymer, 47: 7361-7367.

\section{Figures}




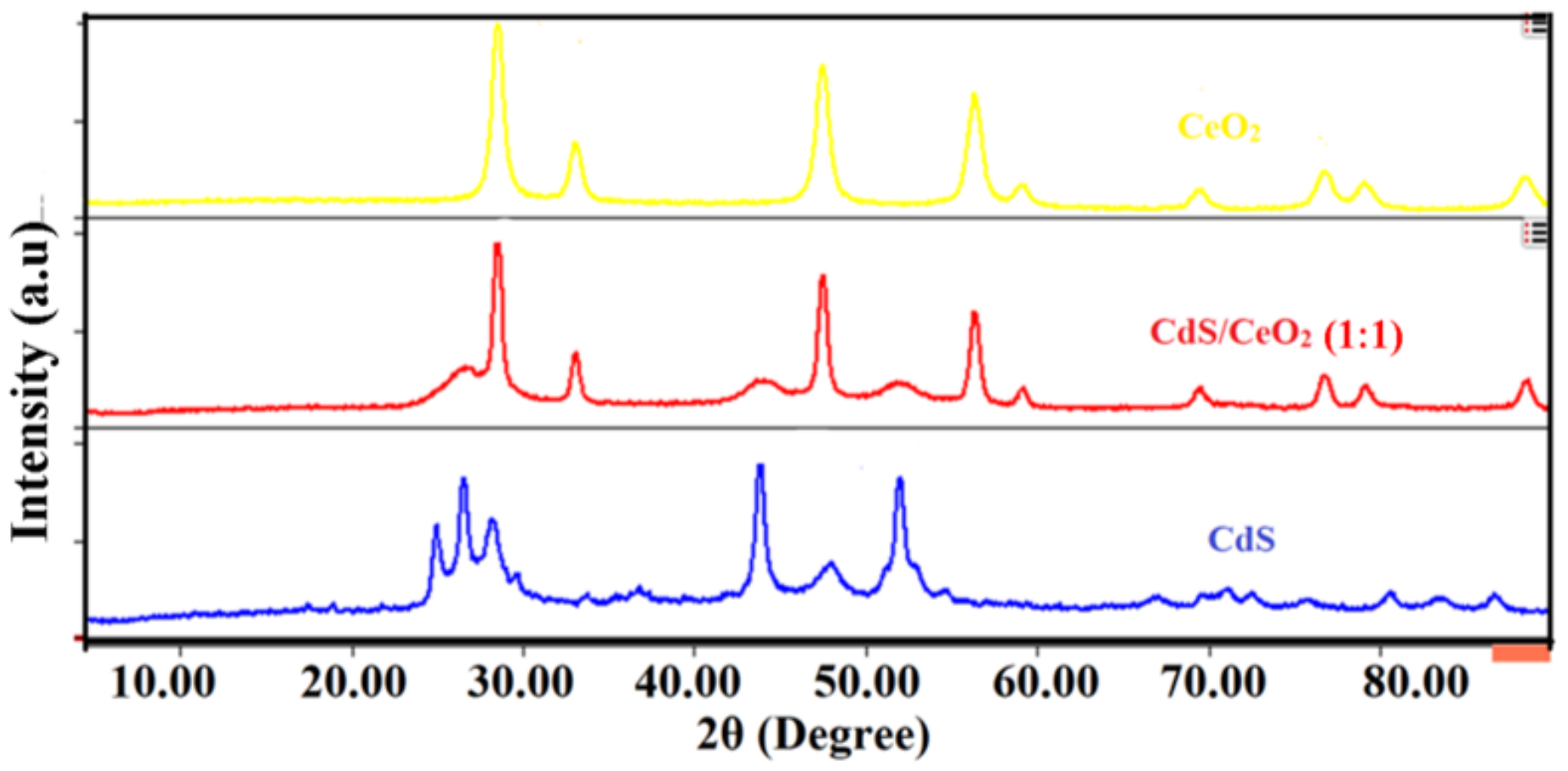

Figure 1

XRD spectra of $\mathrm{CeO} 2, \mathrm{CdS}$ and $\mathrm{CdS} / \mathrm{CeO} 2$ (1:1) photocatalysts 

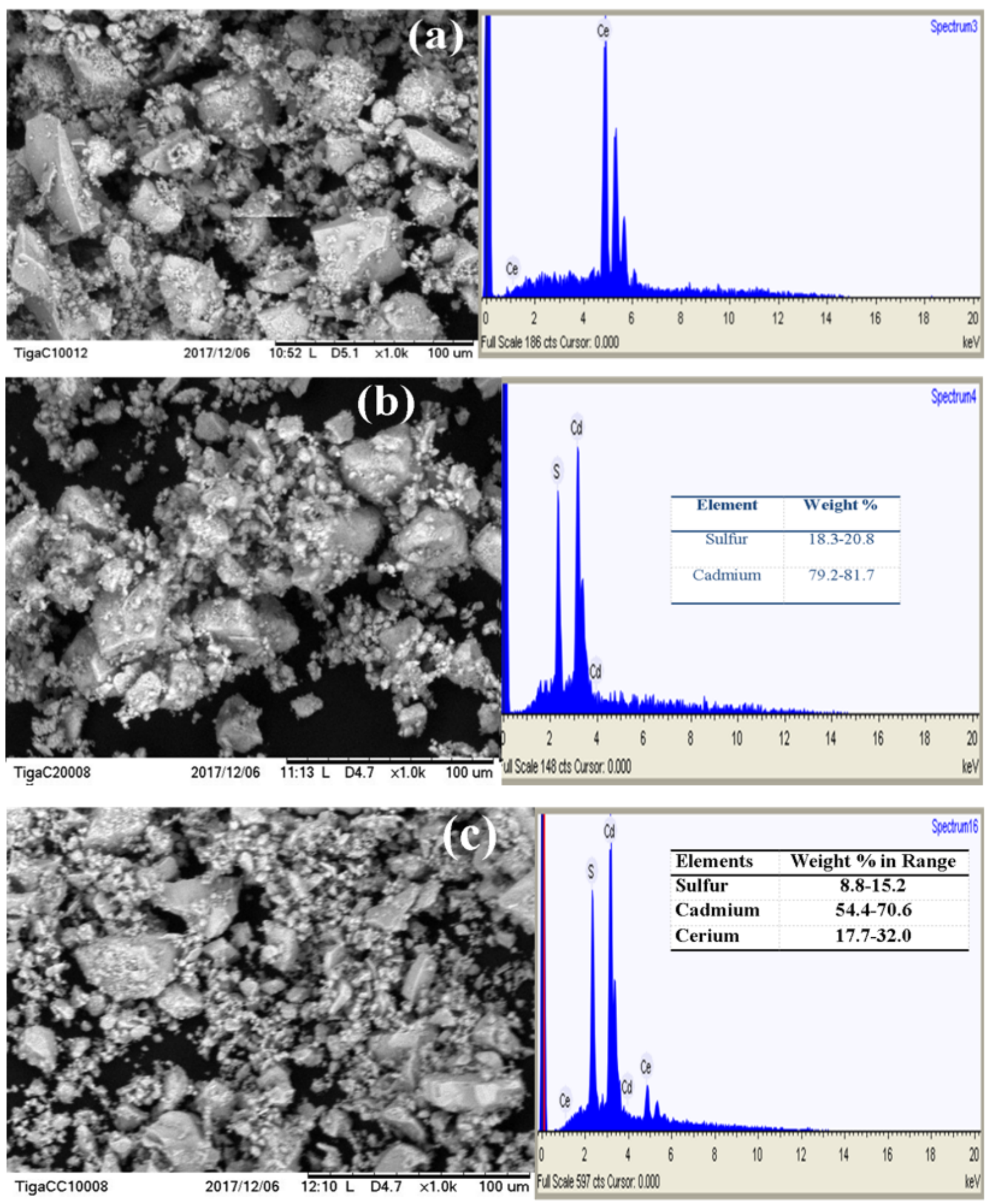

Figure 2

SEM-EDX images of (a) $\mathrm{CeO} 2$, (b) CdS and (c) CdS/CeO2 (1:1) photocatalyst 


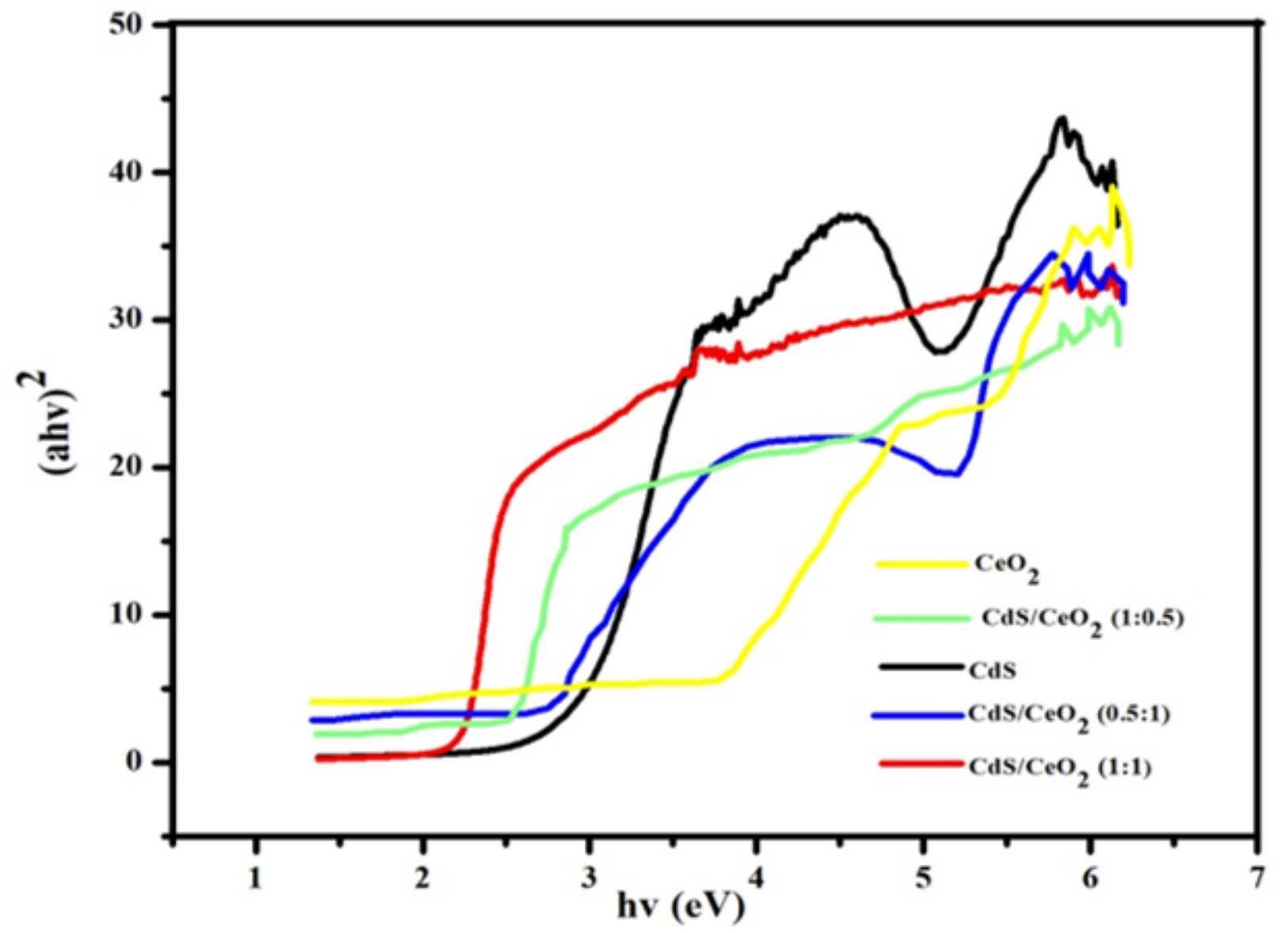

Figure 3

Tauc plot of single (CeO2 and $\mathrm{CdS}$ ) and binary $\mathrm{CdS} / \mathrm{CeO} 2$ (in different molar ratio) photocatalyst 


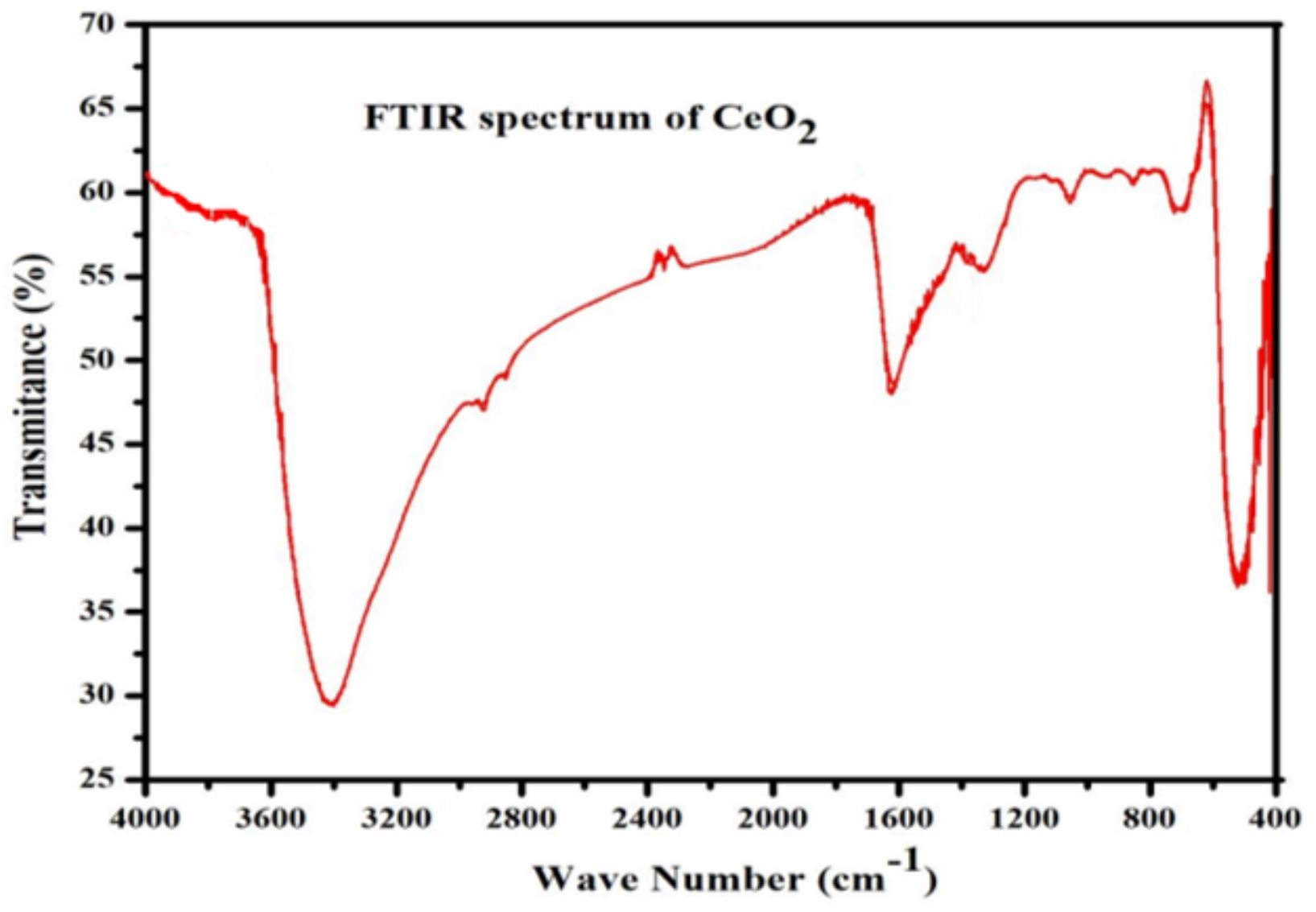

Figure 4

FTIR spectrum of $\mathrm{CeO} 2$ nanoparticle 


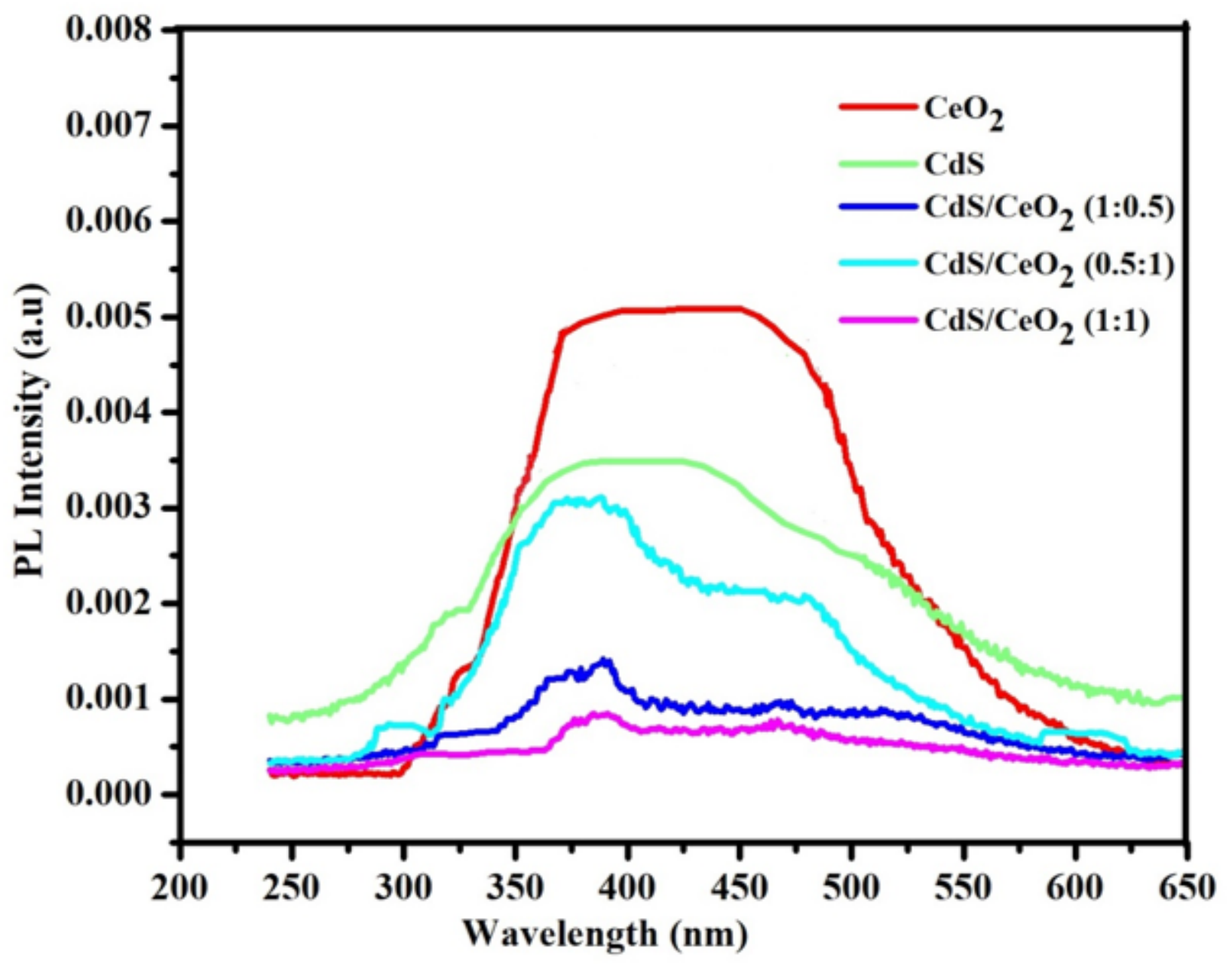

Figure 5

The PL emission spectra of $\mathrm{CeO} 2, \mathrm{CdS}$ and $\mathrm{CdS} / \mathrm{CeO} 2$ (in $0.5: 1,1: 1$ and 1:0.5 molar ratios) photocatalyst 


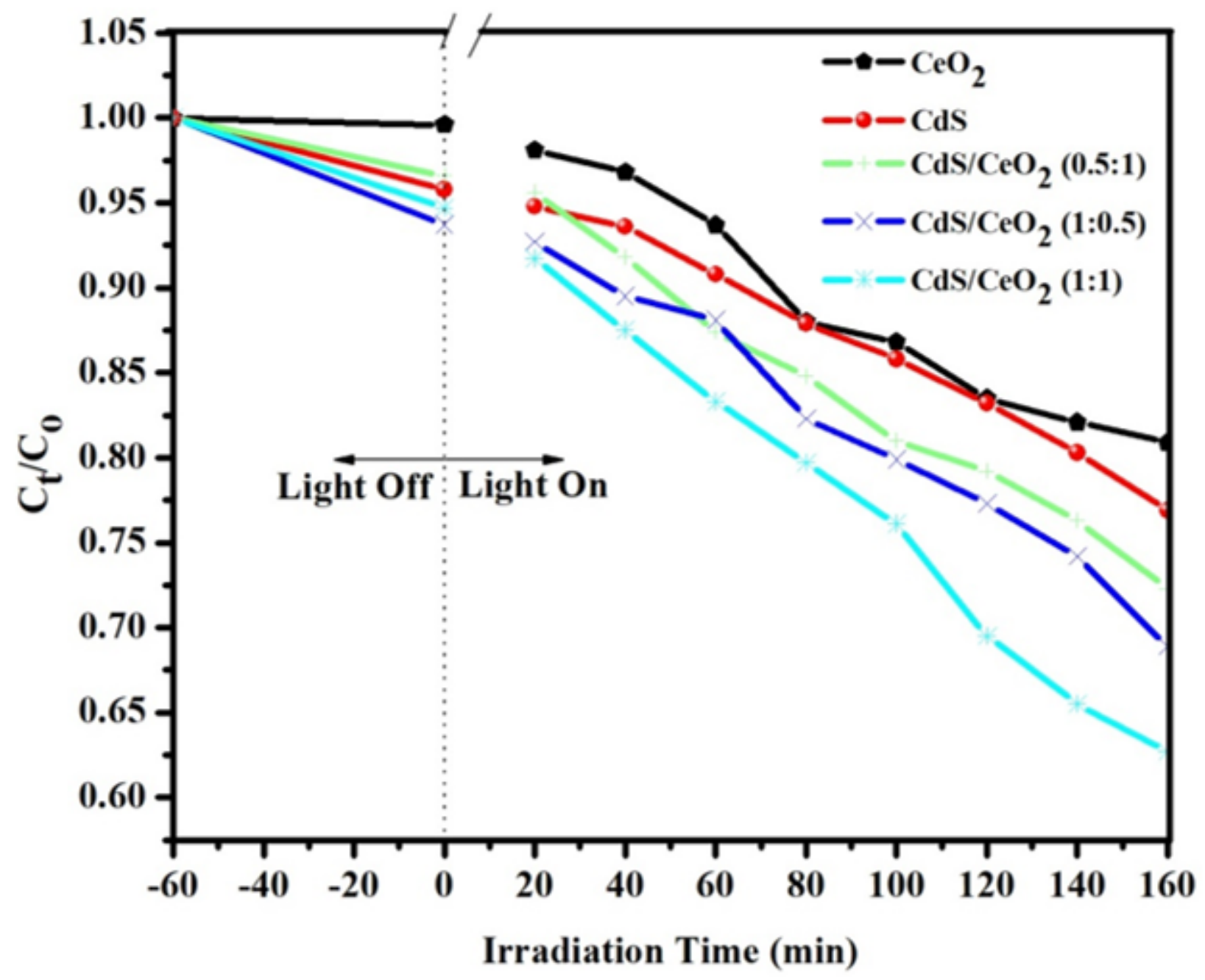

Figure 6

Degradation efficiency of the as-synthesized photocatalyst [CeO2, CdS, CdS/CeO2 (in different ratio) as function of visible irradiation time 


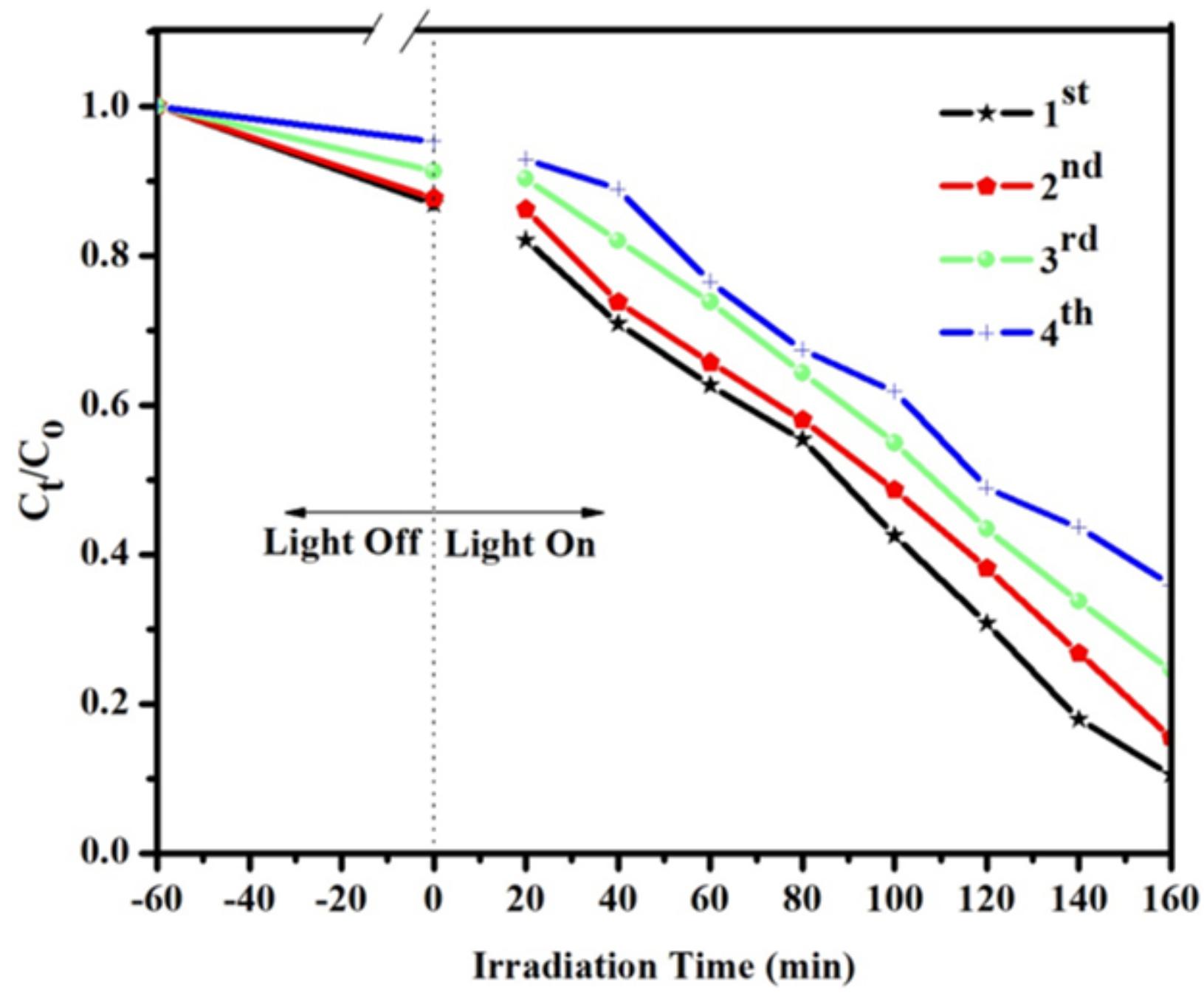

Figure 7

Degradation rate of $\mathrm{MeO}$ using $\mathrm{CdS} / \mathrm{CeO} 2(1: 1)$ photocatalyst as function of irradiation time in different cycles (load at $0.15 \mathrm{~g} / \mathrm{L}$, initial concentration of $\mathrm{MeO}$ at $10 \mathrm{ppm}$ and $\mathrm{pH}$ at 4) 


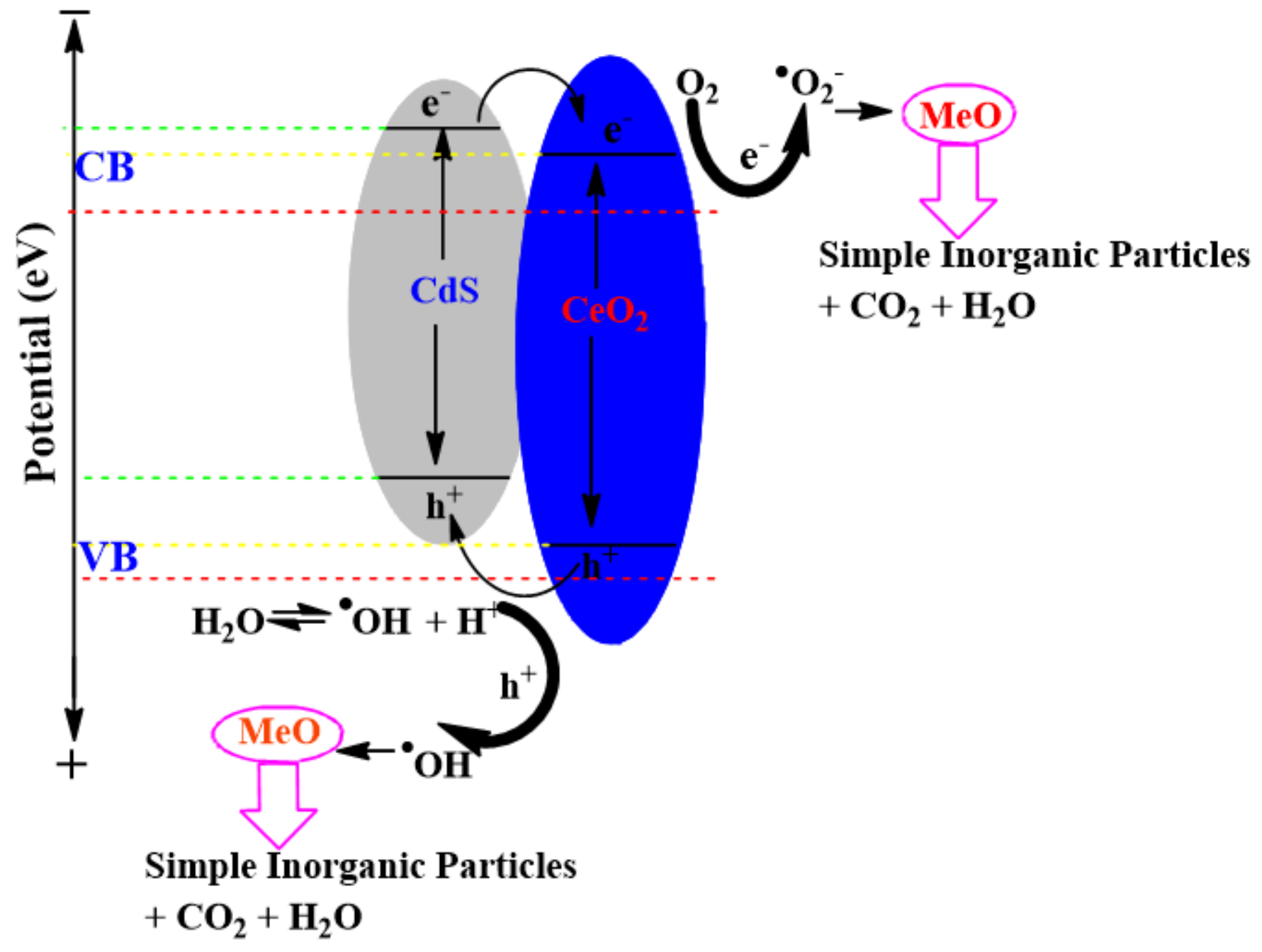

Figure 8

Mechanism of photocatalytic degradation of organic contaminant ( $\mathrm{MeO}$ ) by $\mathrm{CdS} / \mathrm{CeO} 2$ photocatalyst under visible light irradiation

\section{Supplementary Files}

This is a list of supplementary files associated with this preprint. Click to download.

- SupportiveAppendixes.png 